\title{
Análisis espacial y temporal de campos de dunas submarinas en la costa de Yucatán, México
}

\author{
Spatial and temporal assessment of submarine dune fields on the coast of Yucatan, Mexico
}

\section{Eduardo Cuevas', Ma. de los Ángeles Liceaga-Correa1, Leonardo Arellano-Méndez ${ }^{1,2}$, Luis A. Rincón-Sandoval ${ }^{1}$, Guadalupe Mexicano-Cíntora ${ }^{1}$, Jorge I. Euán-Ávila ${ }^{1}$, Héctor Hernández-Núñez ${ }^{1}$ y Sandor Mulsow ${ }^{3}$}

${ }^{1}$ Centro de Investigación y de Estudios Avanzados, Instituto Politécnico Nacional, Unidad Mérida, Km. 6 Antigua Carretera a Progreso, C.P. 97310, Mérida, Yucatán, México. ecuevas@mda.cinvestav.mx

${ }^{2}$ Universidad Veracruzana, Instituto de Ciencias Marinas y Pesquerías, Cuerpo Académico de Arrecifes Coralinos, Calle Independencia $\mathrm{N}^{\circ} 30,2^{\circ}$ Piso, Col. Centro, Boca del Río, Veracruz, C.P. 94290, México

${ }^{3}$ Instituto de Ciencias Marinas y Limnológicas, Universidad Austral de Chile, Casilla 567, Valdivia, Chile

\begin{abstract}
The marine sedimentary deposits are a widely attended theme in the world because of its oceanographical, ecological, social and economical transcendence. Those deposits are part of very important sediment reservoirs on the coast that feed and protect sandy beaches, and are key habitat for several benthic species. On the coast of Yucatan (Mexico) there are conspicuous sedimentary deposits forming well structured and outstanding submarine dune swarms, close to the shoreline at the localities of Dzilam de Bravo, San Felipe and El Cuyo. The objective of this research was to assess the spatial disposition and inter-decadal movements of these dune fields. We used standardized satellite images analyses, validated with seismic profiles and a basic sedimentological description of the identified structures in the field. The dunes showed different magnitude position changes, with estimated net annual movement rates between $2.94 \mathrm{~m}^{\text {year }}{ }^{-1}$ and $10.83 \mathrm{~m}$ year ${ }^{-1}$, heading mainly northwest. The spatial disposition of these dunes was confirmed by the field data, the smallest dunes detected with the satellite images were $0.31 \mathrm{~m}$ high, conformed by medium, conformed by medium and fine sand sediments. It is suggested that the orientation of the shore line and wave incidence, jointly with the dominant currents in the zone, determine the formation of these sediment accumulations in the region. This evaluation presents an innovative and confident approach for the study of submarine dunes in shallow waters, using remote sensing incomes and standardized spatial analyses. These findings set basis for a systematic monitoring of these marine systems, and contributes with original information on the study and understanding of the coastal marine processes in Mexico.
\end{abstract}

Key words: Dune fields, dune movements, sub-bottom profiles

Resumen.- Los depósitos marinos sedimentarios son un tema de estudio ampliamente abordado debido a su trascendencia oceanográfica, ecológica, social y económica, ya que forman parte de los reservorios más importantes de sedimentos, alimentan y protegen las playas, y son el hábitat de numerosas especies bentónicas. En la costa del estado de Yucatán (México) existen campos conspicuos de depósitos sedimentarios que forman dunas submarinas bien estructuradas y sobresalientes en el litoral, aledaños a los puertos de Dzilam de Bravo, San Felipe y El Cuyo. El objetivo de este trabajo fue evaluar la conformación espacial de estos campos de dunas y sus movimientos registrados en décadas. Para esto se utilizaron técnicas estandarizadas de análisis de imágenes satelitales, validadas con perfiles sísmicos del sub-fondo y un análisis sedimentológico básico para verificación de las estructuras identificadas en campo. Las dunas mostraron cambios en su posición de distintas magnitudes, estimándose tasas de movimiento anual neto de entre 2,94 m año-1 y 10,83 m año-1, en sentido dominante hacia el noroeste. La disposición espacial de las dunas fue confirmada por los datos de campo, reportándose el registro de dunas con alturas mínimas de $0,31 \mathrm{~m}$ con las imágenes satelitales, conformadas principalmente por sedimentos del tipo arena fina y media. Se sugiere que la orientación de la línea de costa, en conjunto con la orientación del oleaje y corrientes dominantes actúa de forma determinante sobre la formación de estas acumulaciones sedimentarias en la región. Este trabajo presenta una aproximación innovadora y confiable para el estudio de dunas submarinas en aguas someras con base en herramientas de percepción remota y análisis espaciales estandarizados. Los hallazgos aquí reportados sientan bases para el monitoreo sistemático de estos sistemas marinos, y contribuye con información inédita en el estudio y entendimiento de los procesos marinos y costeros en México.

Palabras clave: Campos de dunas, movimiento de dunas, perfiles sub-fondo 


\section{INTRODUCCIÓN}

La dinámica y estructura de los depósitos sedimentarios sumergidos en zonas costeras, han sido ampliamente estudiados en la última década y en diferentes partes del mundo debido al rol que juegan en la protección de ecosistemas e intereses para el hombre, así como por su valor dado por los hábitats que ellos mismos conforman (Tucker \& Wright 1990). Su análisis y monitoreo se ha hecho mediante diferentes técnicas, entre las que se encuentran la extracción de núcleos de sedimento, la ecosonografía del fondo marino y la reflexión sísmica de alta resolución (Bartholdy et al. 2004, Van Dijk \& Kleinhans 2005, Ernstsen et al. 2006, Schmitt et al. 2007, Garlan et al. 2008, Garlan 2009¹, Gómez et al. 2010).

La presencia o desarrollo de estos depósitos se asocia con la morfología del fondo marino, la cual afecta características como la rugosidad del fondo y procesos como la atenuación de olas y el transporte de sedimento, todo esto bajo condiciones específicas de orientación de la línea de costa respecto a los ángulos de incidencia de oleaje y las corriente que actúan sobre ella (Garlan 2009¹).

Alrededor del mundo existen estudios sobre estimación de la tasa de movimiento de dunas, desplazamientos que son producto de las condiciones de oleaje, viento y mareas dominantes en la zona de interés, así como a movimientos asociados al paso de tormentas en la región (Le Bot \& Trentesaux 2004, Van Dijk \& Kleinhans 2005).

En el estado de Yucatán, México existen dunas submarinas comúnmente conocidas como 'bajos' o 'blanquizales', que representan ecosistemas en equilibrio dinámico y que se sugiere tienen una función determinante en la protección de la línea costera y los ecosistemas así como de los asentamientos humanos cercanos (Cuevas et al. 2013).

Dado que la península de Yucatán es una zona expuesta al paso de tormentas tropicales de diferente magnitud, es razonable considerar que estos eventos meteorológicos tengan efecto en la disposición espacial de las dunas submarinas (Houthuys et al. 1994, Larcombe \& Carter 2004). En el período de 1985 al 2000 se registraron 3 tormentas tropicales cuyos centros cruzaron entre Dzilam de Bravo y Cabo Catoche (Fig. 1). De estos, un huracán fue categoría 5 (Gilberto en 1988), y 2 depresiones tropicales (Opal en 1995 y Gordon en el 2000)².
En contraste, para el período 2000 al 2011 se registraron 8 tormentas tropicales, 3 huracanes (Emily clase 4 en 2005, Wilma clase 4 en 2005, Ida clase 1, 2009), 4 tormentas tropicales (Claudette en 2003, Olga en 2007, Dolly en 2008, Rina en 2011), y una depresión tropical (Cindy en 2005)².

Dada el impulso turístico del estado de Yucatán, así como la importancia ecológica, social y económica de los ecosistemas marinos costeros y de las especies que alberga, la ubicación y caracterización de los campos de dunas submarinas son aspectos importantes, por ello se infiere que tienen un papel significativo como fuente de sedimento para las líneas de costa (Hequette \& Aernous 2010). En el caso particular de la playa en la península de Yucatán, ésta se encuentra expuesta a procesos erosivos serios en segmentos particulares (Cuevas-Jiménez \& Euán-Ávila 2009); sin embargo, para México, no se han encontrado reportes de estudios previos que incluyan una evaluación detallada de depósitos sedimentarios submarinos costeros.

Los objetivos del presente estudio fueron analizar espacial y temporalmente 3 campos de dunas submarinas en zonas aledañas a la línea de costa en los puertos de Dzilam de Bravo (DBR), San Felipe (SFE) y El Cuyo (ELC) en el estado de Yucatán, México, incluyendo una evaluación morfológica de las dunas que los componen y las propiedades granulométricas de los sedimentos superficiales en ellas. Se postuló la hipótesis que los campos de dunas estudiados se mueven a una misma tasa decadal neta, y lo hacen en un sentido de movimiento concentrado en un vector medio (rumbo dominante). Con el presente estudio, se entrega un aporte al conocimiento de la estructura y dinámica de estos campos de dunas submarinas, cuya información es clave para su valoración ecológica y económica, así como un mejor entendimiento de su función en el mantenimiento del equilibrio dinámico costero de la región.

\section{MATERIALES Y MÉTODOS}

\section{ÁREA DE ESTUdio}

Yucatán se encuentra en la porción norte de la península de Yucatán, en el sureste de México, rodeada por el Golfo de México y Mar Caribe (Fig. 1). La península es de origen cárstico y permaneció sumergida durante el Cretácico y

\footnotetext{
${ }^{1}$ GIS and mapping of moving marine sand dunes <http://icaci.org/documents/ICC_proceedings/ICC2009/html/refer/2_2.pdf>
}

Fuente: Servicio Meteorológico Nacional, Comisión Nacional del Agua, México 2012 
Terciario (Cabadas-Báez et al. 2010). Esta región se caracteriza por una plataforma continental submarina formada por rocas sedimentarias sobre un basamento cristalino del Paleozoico, el cual sugiere que es una de las estructuras más recientes del territorio mexicano que se originó a partir de un ascenso en el Plioceno-Cuaternario (Lugo-Hubp et al. 1992). En lo que se refiere a su orografía, no existen accidentes topográficos mayores en la zona, a excepción de la porción sur de la península.

En la península de Yucatán no hay ríos superficiales que aporten material terrígeno al mar, pero se reconocen flujos laminares subterráneos a través de las estructuras cársticas (Perry et al. 2009, Cabadas-Báez et al. 2010, Solleiro-Rebolledo et al. 2011). La zona costera al norte de la península conforma una planicie que comprende desde las localidades de Celestún en el oeste a Cabo Catoche al este, y se caracteriza por ser una franja estrecha de depósitos marinos recientes de origen carbonatado biogénico y un litoral de acumulación (Lugo-Hubp et al. 1992, Capurro et al. 2002).
La zona marina se caracteriza por presentar un oleaje de baja energía, corrientes superficiales dominantes de este a oeste (Enríquez et al. 2010) y un transporte potencial de sedimentos en el mismo sentido como resultado del oleaje (Appendini et al. 2012).

Esta región está bajo la influencia de los vientos alisios durante todo el año, provenientes del este y sureste principalmente, con velocidades entre 2 y $10 \mathrm{~m} \mathrm{~s}^{-1}$, y el régimen de lluvias marca el patrón climático en secas (marzo-mayo), lluvias (junio-octubre) y 'nortes' o tormentas estacionales (noviembre a febrero) con vientos de hasta $90 \mathrm{~km} \mathrm{~h}^{-1}$, lluvia moderada y descensos de temperatura de hasta $15^{\circ} \mathrm{C}$ en $24 \mathrm{~h}$. La temporada de huracanes (agosto a noviembre), se sobrepone a las temporadas de lluvias y nortes (Álvarez-Góngora \& Herrera-Silveira 2006), con vientos de hasta $10 \mathrm{~m} \mathrm{~s}^{-1}$ (Enríquez et al. 2010), lo que aumenta la intensidad de los procesos costeros que provocan cambios importantes en la morfología del litoral (Capurro 2002, Cuevas-Jiménez \& Euán-Ávila 2009).

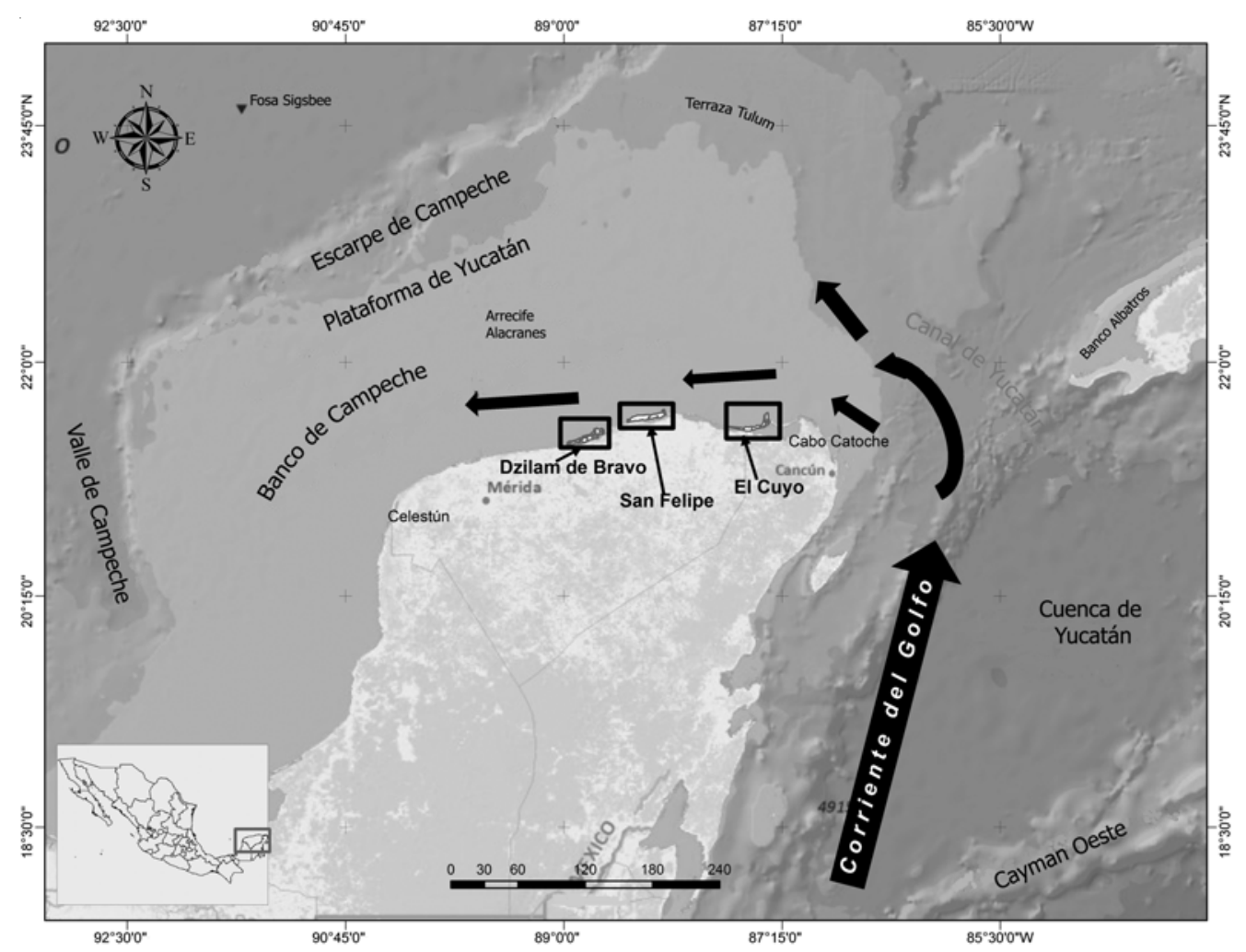

Figura 1. Localización de las áreas de estudio (encerradas en rectángulos negros). Las flechas de color negro esquematizan la dirección del flujo de corrientes marinas superficiales dominantes en la región de la península de Yucatán, México. Velocidades de corriente en la esquina noreste de la península y en el centro del Canal de Yucatán tomadas de Enríquez et al. (2010) / Location of the assessed areas (enclosed in black rectangles). Black arrows outline the dominant flux direction of sea surface currents in the region adjacent to the Yucatan peninsula, Mexico. Sea surface currents' speeds were taken from Enríquez et al. (2010) 


\section{ESTRUCTURA ESPACIAL DE LOS CAMPOS DE DUNAS}

Se seleccionó un conjunto de imágenes satelitales del sensor Landsat ETM y ETM+ del período entre 1985 y 2011, con las mejores condiciones de calidad de adquisición (estándar de calificación de 7 a 9, donde 9 es la máxima calidad, y está definida por errores durante el procesamiento de la imagen original, y por artefactos en las imágenes al inspeccionarse visualmente) y cobertura de nubes en la escena total $(<10 \% \text { USGS })^{3}$.

Debido a variaciones climáticas en la región, la disponibilidad de imágenes satelitales con calidad suficiente para estos análisis fue diferente en cada una de las zonas de estudio. Las imágenes seleccionadas para el análisis en DBR fueron de los años 1985, 2000 y 2011; para SFE 1987, 2000 y 2010; y para ELC 1989, 2000 y 2011. Dada la calidad de las imágenes disponibles para estas zonas, no fue posible conjuntar una serie de tiempo consistente para las 3 áreas con un intervalo de tiempo de 1 año, como sería lo ideal, por lo que se optó por adoptar una escala decadal para la evaluación de esta aproximación de análisis espacial.

Mediante procesamiento y análisis de imágenes utilizando el programa TNTmips ${ }^{\circledR}$, se redujo el efecto atmosférico y el efecto de la profundidad por la columna de agua en las imágenes (Mumby \& Edwards 2000), con lo cual se mejoró la discriminación radiométrica del fondo marino en los campos de dunas estudiados, incrementando la eficiencia de los análisis posteriores. Se realizó una verificación visual de las diferencias en el co-registro entre imágenes, y se confirmaron diferencias menores a $30 \mathrm{~m}(<1$ pixel), nivel aceptable para evaluaciones temporales utilizando estas imágenes (Bindschadler \& Scambos 1991, Scambos et al. 1992).

Con el propósito de utilizar una aproximación de análisis de cuencas para la evaluación espacial de los campos de dunas submarinas, los valores digitales de las imágenes fueron invertidos. De esta manera, las zonas más elevadas del fondo marino (dunas) se representaban como depresiones, o zonas más profundas (menores valores digitales de las imágenes), y los canales entre dunas o zonas sin ellas se representaron como las más elevadas (mayores valores digitales de las imágenes). El análisis de cuencas reconoce dichas zonas más bajas y cuantifica los flujos por esas zonas, y con base en la hipótesis de crecimiento por saltos de las dunas (Flemming 2000, Xu et al. 2008), éstas fueron vectorizadas utilizando la información radiométrica derivada de las imágenes satelitales.

Se consideró la definición de sub-zonas dentro de los campos de dunas para evaluar diferencias espaciales en su estructura espacial, para lo que se realizó un análisis de componentes principales (PCA) utilizando las bandas del espectro azul de las imágenes seleccionadas. La imagen resultante del segundo componente sirvió para identificar las sub-zonas (para el análisis se definió como el área drenada por una red de ramas de flujo), utilizando el módulo Modeling Watershed Geomorphology del programa TNTmips ${ }^{\circledR}$.

Para cada campo de dunas se calcularon los valores de las características descriptivas, área promedio ocupada por sub-zona $\left(\mathrm{km}^{2}\right)$, número promedio de crestas (dunas submarinas), mediana de la longitud total de las dunas (m) (debido a la dispersión observada de los valores esta medida central es la más apropiada) (Zar 1994), densidad promedio de dunas (número promedio de dunas $\mathrm{km}^{-2}$ ), y proporción de jerarquías de duna con base en el índice Horton (Smith 2010) que define categorías de las dunas considerando las uniones de 2 o más dunas tributarias para la formación de dunas de mayor dimensión o una jerarquía mayor. Su aplicación tiene fundamento también en la hipótesis de crecimiento por saltos de las dunas submarinas, propuesta por Flemming (2000) y Xu et al. (2008). Por último, se evaluaron correlaciones entre atributos espaciales de los campos.

\section{Movimiento DE LAS DUNAS}

Para la cuantificación del movimiento de las dunas se digitalizaron las dunas identificadas en las imágenes satelitales para los 3 sitios estudiados. De la comparación visual entre vectores de los 3 tiempos se seleccionaron aquellas dunas que fueron identificables en al menos 2 de las imágenes.

La medición del desplazamiento decadal neto entre imágenes de cada sitio, así como el rumbo del mismo, fue realizado con la herramienta de medición digital en el programa TNTmips ${ }^{\circledR}$, midiendo de forma directa la distancia entre crestas de las dunas. Se realizaron pruebas de análisis de varianza (supuestos de normalidad y homocedasticidad cumplidos, $P>0,05$ ) para la evaluación de diferencias de movimientos entre períodos decadales. También se analizaron parámetros estadísticos circulares para los datos de rumbo de movimientos de las dunas.

\footnotetext{
${ }^{3}<$ http://earthexplorer.usgs.gov/resources/helpdocs/dict/landsat_dictionary.html>. US Department od the Interior US Geological Survey.
} 


\section{Perfiles sísmicos}

Se realizó una campaña para verificación en campo de las estructuras sedimentarias submarinas identificadas con las imágenes satelitales. Entre octubre y noviembre de 2010, se colectaron datos con un perfilador sísmico de fuente acústica tipo chirp (Strata Box, Syqwest, Inc.) de $10 \mathrm{kHz}$. Se recorrieron transectos perpendiculares a la costa de $3 \mathrm{~km}$ de longitud sobre las áreas de dunas, a profundidades de entre 2 y $5 \mathrm{~m}$.

Los datos fueron analizados con el software Kingdom Suite 8.7 (IHS Inc. 2012) ${ }^{4}$, se aplicó un filtro pasa banda de 1 a $7 \mathrm{kHz}$ a cada conjunto de datos sísmicos colectados. Utilizando el mismo programa se realizaron mediciones de altura de la duna sobre las imágenes de perfiles sísmicos obtenidos. Se usó la herramienta Ruler, con el parámetro Deep shift.

\section{AnÁLisis SEdimentológico}

En cada uno de los 3 campos se definieron 3 sitios cercanos a los transectos barridos, en ellos se colectaron muestras de sedimento superficial ( $\mathrm{N}=9$ ) de forma manual, con ayuda de un equipo de buceo autónomo. Se utilizó la técnica estandarizada de Folk (1980), con muestras de 50 $\mathrm{g}( \pm 0,001)$ que fueron procesadas con un tren de 7 tamices $(\varphi:-1,0,1,2,3,4$ y 5$)$ por 15 min.

Se estimaron los parámetros estadísticos gráficos descritos por Folk (1980), media, desviación estándar, asimetría y curtosis. Adicionalmente, con el cálculo de los valores de diámetro medio (D50) de las muestras se clasificaron los sedimentos con la escala propuesta por este mismo autor.

\section{Resultados}

\section{ESTRUCTURA ESPACIAL DE LOS CAMPOS DE DUNAS}

Dado que el análisis con aproximación de cuencas permitió reconocer sub-zonas en las que no habían dunas (estas sub-zonas son indicadas por sus características de acumulación o aporte de sedimento en este caso - Tutorial Modeling Watershed Geomorphology de TNTmips $\left.{ }^{\circledR}\right)$, se seleccionaron sólo aquellas sub-zonas en las cuales se encontraron dunas discernibles y consistentes en al menos 2 tiempos, definiéndose un total de 18 sub-zonas de estudio en DBR, 9 en SFE y 7 en ELC (Fig. 2).

El rango de valores de la mediana de longitudes y densidades promedio de las dunas, en orden decreciente, fueron de 290-470 m de longitud y 2,93 $( \pm 1,3)$ dunas $\mathrm{km}^{-2}$

\footnotetext{
${ }^{4}<$ http://www.ihs.com>
}

en ELC, seguido de SFE con dunas entre 400-711 m de longitud y $9( \pm 2,7)$ dunas $\mathrm{km}^{-2}$, y DBR con longitudes entre 290-470 m y 2,93 ( $\pm 1,3)$ dunas km² (Tablas 1,2 y 3).

Tabla 1. Características descriptivas del campo de dunas en Dzilam de Bravo, Yucatán / Descriptive features for the dune field at Dzilam de Bravo, Yucatan

\begin{tabular}{|c|c|c|c|c|c|}
\hline Sub-zona & $\begin{array}{c}\text { Área } \mu \\
\left(\mathrm{km}^{2}\right)\end{array}$ & $\begin{array}{l}\text { Número } \mu \text { de } \\
\text { crestas }( \pm D . E)\end{array}$ & $\begin{array}{c}\text { Long. }(\mathrm{m}) \\
\mu \text { crestas }( \pm \mathrm{D} . \mathrm{E} .)\end{array}$ & $\begin{array}{l}\text { Mediana Long. } \\
\text { (m) Crestas }\end{array}$ & $\begin{array}{c}\text { Densidad } \\
\mu \text { crestas } \\
\left(\mathrm{km}^{-2}\right)\end{array}$ \\
\hline 2 & 19,5 & $87,0(6,0)$ & $511,1(345,1)$ & 469,7 & 4,5 \\
\hline 3 & 3,0 & $15,3(6,7)$ & $429,9(262,0)$ & 394,0 & 5,1 \\
\hline 4 & 2,7 & $6,3(1,5)$ & $395,5(259,9)$ & 434,6 & 2,4 \\
\hline 5 & 4,3 & $15,7(6,0)$ & $437,7(374,7)$ & 319,9 & 3,7 \\
\hline 6 & 4,6 & $8,3(0,6)$ & $424,7(26,9)$ & 387,0 & 1,8 \\
\hline 8 & 14,3 & $41,3(7,0)$ & $450,9(435,9)$ & 348,7 & 2,9 \\
\hline 11 & 3,4 & $13,5(--)$ & $393,3(317,5)$ & 290,5 & 4,0 \\
\hline 12 & 14,0 & $17,7(11,5)$ & $388,2(321,5)$ & 308,4 & 1,3 \\
\hline 13 & 7,7 & $21,3(9,0)$ & $379,8(286,3)$ & 329,6 & 2,8 \\
\hline 14 & 6,1 & $26,0(9,6)$ & $518,4(503,1)$ & 374,5 & 4,3 \\
\hline 15 & 7,9 & $29,7(16,4)$ & $377,4(304,1)$ & 316,9 & 3,8 \\
\hline 16 & 14,4 & $14,3(9,8)$ & $472,0(432,1)$ & 357,0 & 1,0 \\
\hline 17 & 8,5 & $8,7(4,7)$ & $427,1(317,3)$ & 410,9 & 1,0 \\
\hline 18 & 6,2 & $17,0(4,2)$ & $360,4(272,8)$ & 325,9 & 2,7 \\
\hline
\end{tabular}

Tabla 2. Características descriptivas del campo de dunas en San Felipe, Yucatán / Descriptive features for the dune field at San Felipe, Yucatan

\begin{tabular}{cccccc}
\hline Sub-zona & $\begin{array}{c}\text { Área } \mu \\
\left(\mathrm{km}^{2}\right)\end{array}$ & $\begin{array}{c}\text { Número } \mu \text { de } \\
\text { crestas }( \pm D . E .)\end{array}$ & $\begin{array}{c}\text { Long. }(\mathrm{m}) \\
\mu \text { crestas }( \pm \mathrm{D} . \mathrm{E} .)\end{array}$ & $\begin{array}{c}\text { Mediana Long. Densidad } \\
(\mathrm{m}) \text { Crestas }\end{array}$ & $\begin{array}{c}\mu \text { crestas } \\
\left(\mathrm{km}^{-2}\right)\end{array}$ \\
\hline & & & & & \\
1 & 0,8 & $7,3(3,2)$ & $724,7(140,5)$ & 711,6 & 8,8 \\
2 & 1,1 & $16,3(6,4)$ & $512,3(45,3)$ & 537,1 & 15,5 \\
3 & 2,7 & $25,3(4,0)$ & $465,0(128,7)$ & 400,6 & 9,5 \\
4 & 62,9 & $412,0(104,0)$ & $510,7(45,4)$ & 520,6 & 6,5 \\
5 & 44,1 & $326,0(21,9)$ & $464,8(48,3)$ & 445,5 & 7,4 \\
6 & 1,3 & $12,0(2,6)$ & $480,8(100,2)$ & 475,9 & 9,5 \\
7 & 1,2 & $10,0(2,0)$ & $414,1(31,8)$ & 412,2 & 8,4 \\
8 & 1,5 & $12,7(4,6)$ & $640,0(132,8)$ & 680,9 & 8,6 \\
9 & 2,3 & $15,0(4,0)$ & $587,5(108,4)$ & 610,7 & 6,6 \\
\hline
\end{tabular}

Tabla 3. Características descriptivas del campo de dunas en El Cuyo, Yucatán / Descriptive features for the dune field at El Cuyo, Yucatan

\begin{tabular}{|c|c|c|c|c|c|}
\hline Sub-zona & $\begin{array}{c}\text { Área } \mu \\
\left(\mathrm{km}^{2}\right)\end{array}$ & $\begin{array}{l}\text { Número } \mu \text { de } \\
\text { crestas (tD.E.) }\end{array}$ & $\begin{array}{c}\text { Long. }(\mathrm{m}) \\
\mu \text { crestas }( \pm \mathrm{D} . \mathrm{E} .)\end{array}$ & $\begin{array}{l}\text { Mediana Long. } \\
\text { (m) Crestas }\end{array}$ & $\begin{array}{c}\text { Densidad } \\
\mu \text { crestas } \\
\left(\mathrm{km}^{-2}\right)\end{array}$ \\
\hline 1 & 5,2 & $31,7(2,9)$ & $648,8(497,6)$ & 499,8 & 6,1 \\
\hline 2 & 5,8 & $38,7(8,5)$ & $575,7(476,4)$ & 417 & 6,6 \\
\hline 3 & 21,1 & $118,(26,5)$ & $490,0(374,7)$ & 403,5 & 5,6 \\
\hline 4 & 30,6 & $168,0(53,3)$ & $446,8(301,0)$ & 389,48 & 5,5 \\
\hline 5 & 4,7 & $19,0(3,6)$ & $487,7(408,3)$ & 414,6 & 4,1 \\
\hline 6 & 6,2 & 20,0 (N.D.) & $471,4(420,9)$ & 343,2 & 3,2 \\
\hline 7 & 15,3 & $58,7(17,4)$ & $460,9(371,8)$ & 356,9 & 3,8 \\
\hline
\end{tabular}



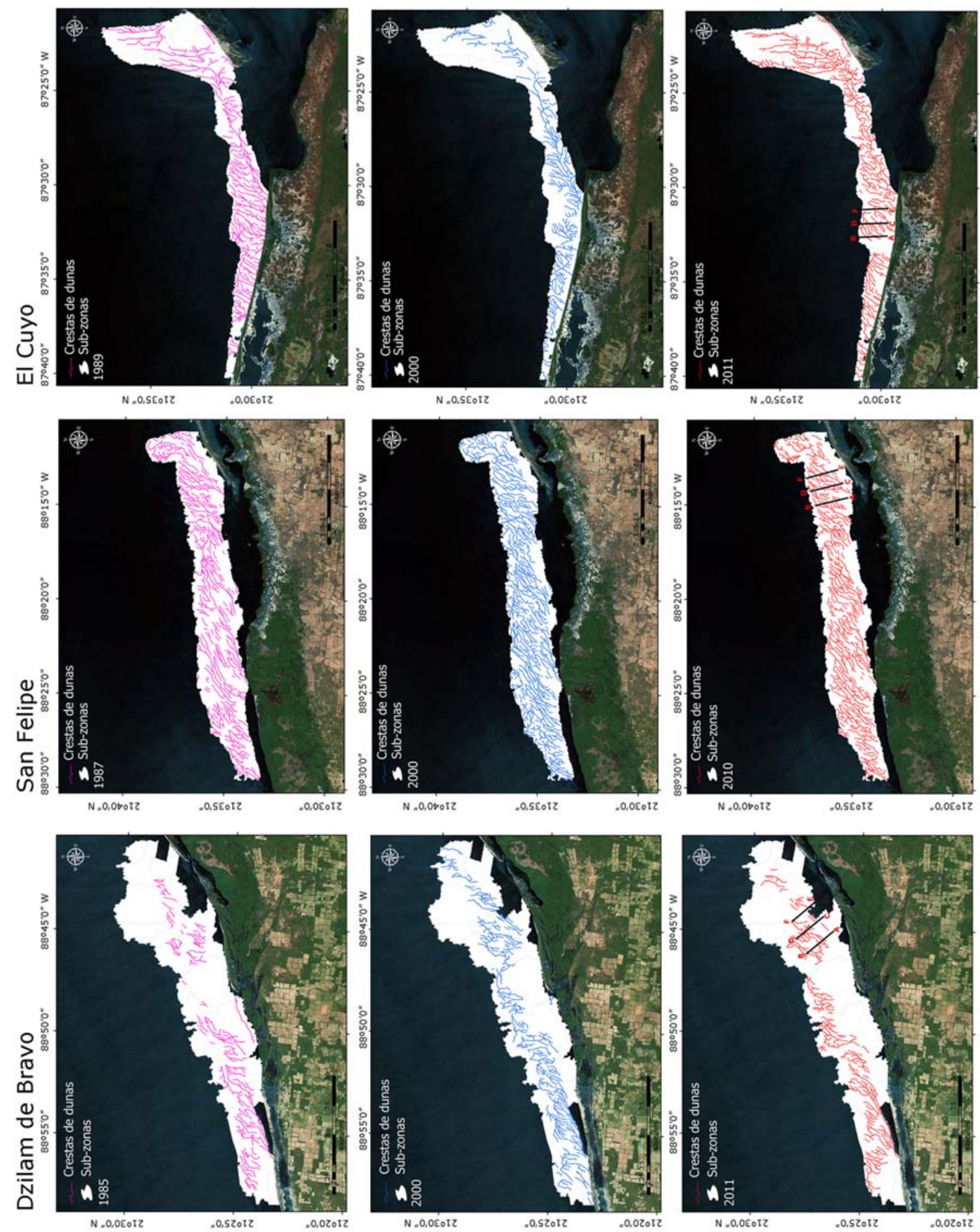

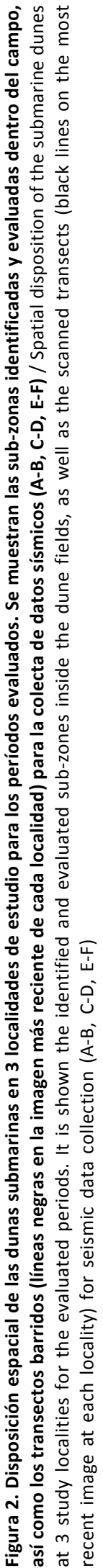


Se determinó una correlación estadísticamente significativa entre el área de las sub-zonas y el número de dunas registradas en cada una de ellas para los 3 campos de dunas (DBR: $\mathrm{r}^{2}=0,48, P=0,0035, \mathrm{n}=14 ;$ SFE: $\mathrm{r}^{2}=0,90$, $P<0,01, \mathrm{n}=9 ; E L C: \mathrm{r}^{2}=0,95, P=0,006, \mathrm{n}=6$ ).

La correlación entre densidad promedio de dunas y el área promedio de las sub-zonas no fue estadísticamente significativa en ninguno de los 3 campos evaluados $(P>$ 0,05).

Por otro lado, la zona de DBR presentó en promedio una mayor proporción de dunas del orden uno, las más simples y aisladas de la red de dunas en el campo ( 30\%), seguidas del 3 ( 26\%) y del 2 ( 25\%), encontrándose diferencias en el orden de las dunas dominantes en las diferentes sub zonas del campo en los años evaluados (Fig. 3). Para SFE, de manera general las dunas de orden uno fueron las dominantes (32\%), seguidas del orden 2 (28\%) y 3 (18\%) (Fig. 3). Finalmente, en ELC, de manera general se presentaron mayormente dunas del orden uno (32\%), seguidas del 2 (29\%) y del 4 (21\%) (Fig. 3).

En algunas sub-zonas (i.e., sub-zonas 6 y 13 en DBR) se observó un incremento en la proporción de dunas con jerarquía más baja entre un año y otro, a la vez que la proporción de dunas de jerarquía más alta disminuyó; y en otros casos fue lo contrario (i.e., sub-zonas 11 y 14).

\section{MOVIMIENTO DE LAS DUNAS}

En el campo de DBR se estimó un desplazamiento promedio de $42,40 \mathrm{~m}$ ( $\pm 16,9$ ) entre los años 1989 y 2000, y de 41,56 m ( $\pm 13,24)$ entre los años 2000 y 2011 (Fig. 4). La diferencia en magnitud de estos desplazamientos entre los 2 períodos no fue estadísticamente significativa $(\mathrm{H}=$ $0,00081, P=0,977$ ). Estos valores permitieron estimar una tasa de movimiento promedio de las dunas de aproximadamente 3,85 m año-1 en el período de 1989 al 2000, y de 3,78 $\mathrm{m}$ año $^{-1}$ en el período 2000 al 2011.

En SFE, el movimiento promedio de las dunas en el período de 1987 al 2000 fue de 52,18 m ( \pm 22,98), y un movimiento de 32,39 m ( $\pm 10,43)$ para el período 20002010. Al comparar la magnitud del movimiento de las dunas entre ambos períodos se denotaron diferencias estadísticamente significativas entre ellas $(\mathrm{H}=5,36, P<$ 0,01). La tasa de movimiento promedio anual estimada para estas dunas fue de 4,01 m año-1 entre 1987 y el 2000, y de 2,94 m año-1 entre el 2000 y 2010.
En lo que respecta a la zona del campo de dunas en ELC, se estimó un movimiento promedio de 119,15 m ( \pm 59,96) en el período 1989 al 2000, y un movimiento promedio de $36,33 \mathrm{~m}( \pm 23,98)$ para el período 2000 al 2011, con una diferencia estadísticamente significativa ( $\mathrm{H}=76,03, P<0,001)$. El movimiento promedio estimado de estas dunas fue de 10,83 $\mathrm{m}$ año-1 entre 1989 y 2000, y de 3,30 m año-1 entre 2000 y 2010.

El rumbo del movimiento de las dunas fue diferente entre campos de dunas, y en algunos casos entre períodos. En DBR y SFE el rumbo promedio en ambos períodos de tiempo fue similar $\left(\sim 315^{\circ}\right)$, y una concentración de los datos alrededor del vector promedio estadísticamente significativa (Fig. 5). En contraste, en ELC los rumbos promedio de movimiento de las dunas fueron estadísticamente distintos entre los 2 períodos evaluados (Watson $\mathrm{U}^{2}$ circular (von Mises) $=1,143, P<0,005, \mathrm{n}=$ 174). Esto sugiere la presencia de factores diferentes en ambos períodos de tiempo.

Es importante mencionar que las dunas evaluadas en las localidades de DBR y SFE están intercaladas con parches de pastos marinos, dominados por Thalassia testudinum, condición que es relevante en la hidrodinámica del área y el movimiento de las dunas.

\section{Perfiles sísmicos}

Los datos sísmicos colectados confirmaron la presencia de las dunas identificadas en las imágenes satelitales. La duna de menor tamaño registrada en el campo fue de 0,31 m.

Con los datos sísmicos también se advirtieron diferencias, aunque no estadísticamente significativas, en la disposición espacial interna en las 3 localidades, con características morfológicas similares entre ellas ( $F=$ 1,65, g.l. $=2, P=0,199$ ). En DBR se observaron dunas de extensión variable sobre el fondo consolidado y con alturas promedio de 0,60 $\mathrm{m}( \pm 0,19, \mathrm{n}=26)$ (Fig. 6). En SFE se observaron dunas con distribución similar a DBR, y dunas continuas de mayor altura hacia la costa. La altura promedio de las dunas en esta localidad fue de 0,52 m ( \pm $0,13, \mathrm{n}=22$ ) (Fig. 6).

En ELC, el depósito sedimentario que conforma el campo de dunas presentó una mayor extensión que en las otras localidades, con dunas interconectadas entre sí y el espesor del depósito sedimentario disminuyendo hacia el norte a medida que se incrementa la profundidad. La altura promedio de las dunas fue de $0,59( \pm 0,18, \mathrm{n}=$ 26) (Fig. 6). 


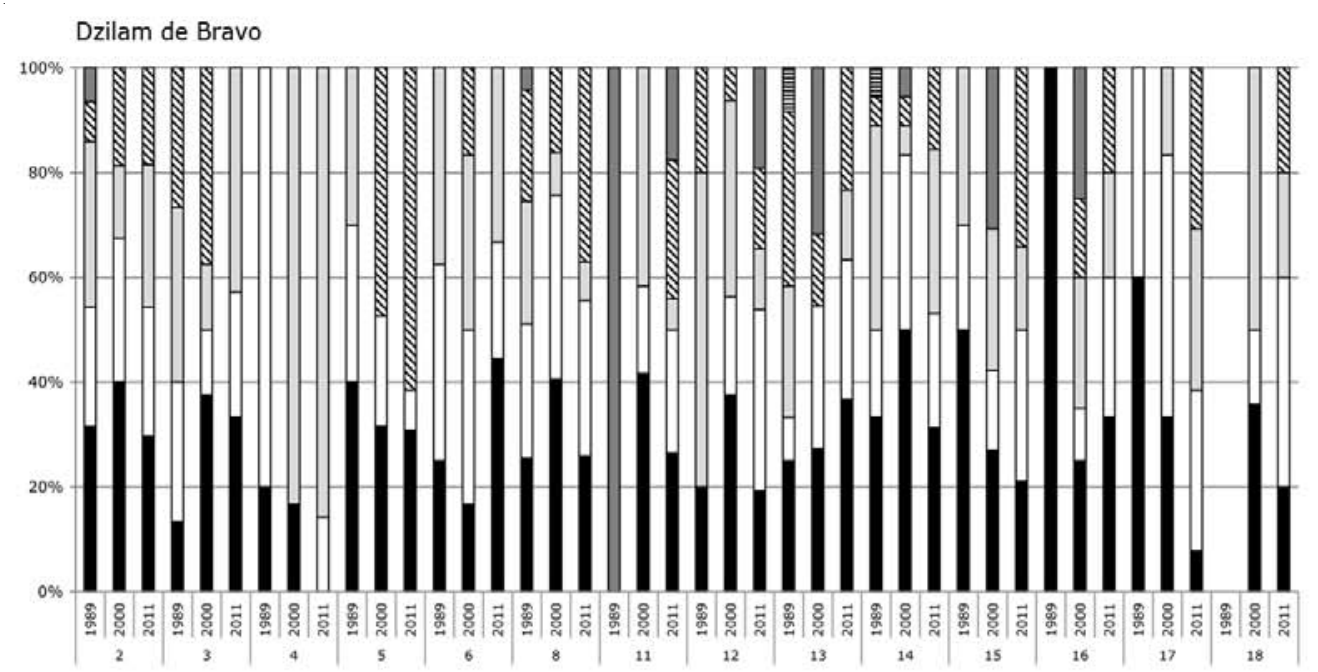

Sub-zonas

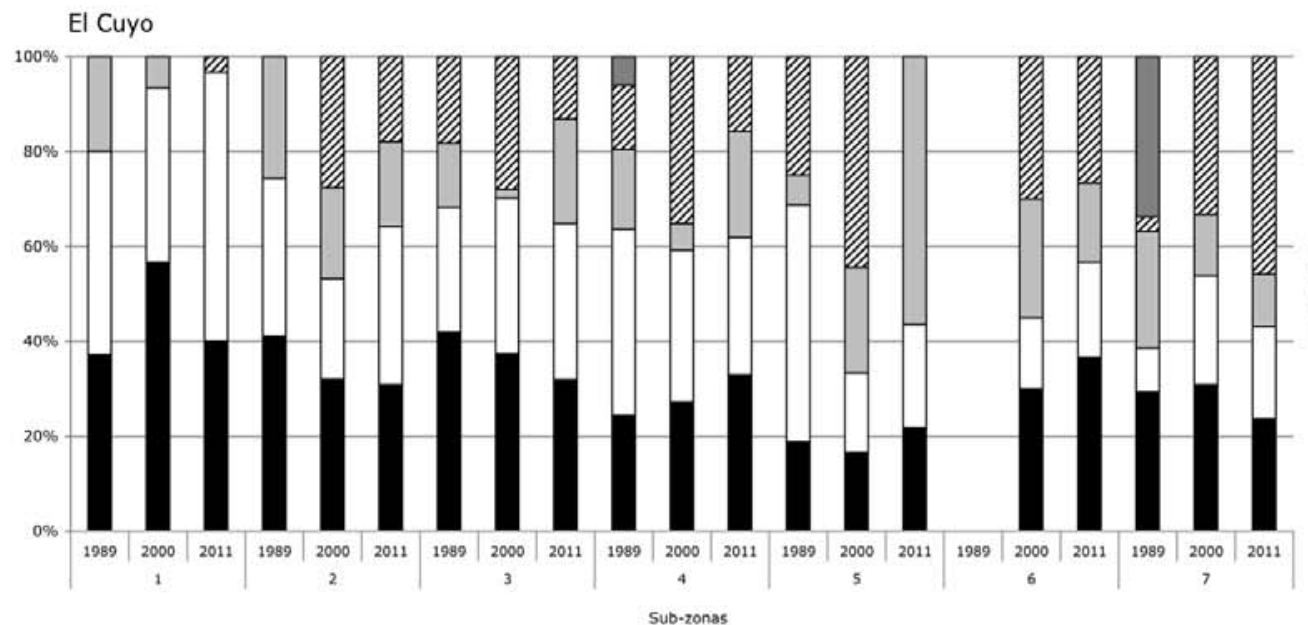

- Horton1 口Horton2

口Horton3 $\mathbf{S H o r t o n} 4$

口Horton5 日Horton6

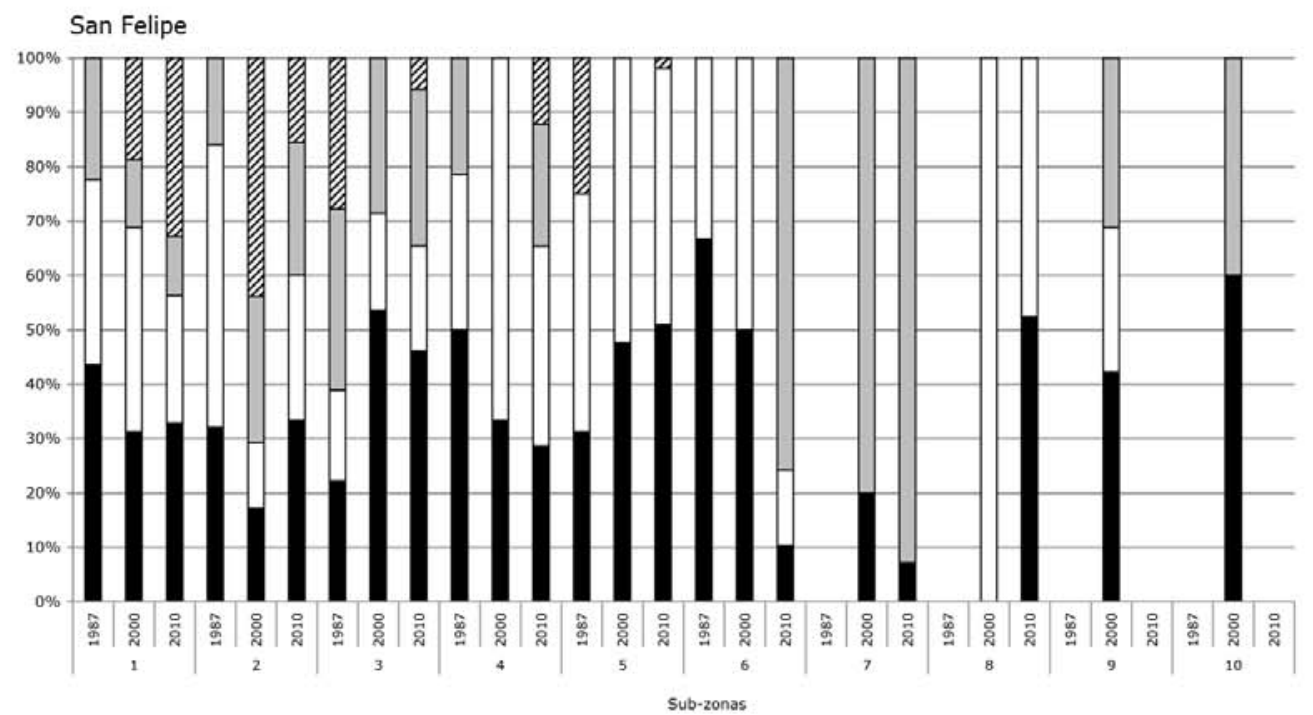

Figura 3. Gráfico de porcentajes acumulados de las jerarquías de dunas (índice Horton) para las 3 localidades de estudio en los períodos de tiempo evaluados / Accumulated percentages plot for the dune hierarchies (Horton index) at the 3 study localities in the evaluated periods of time 

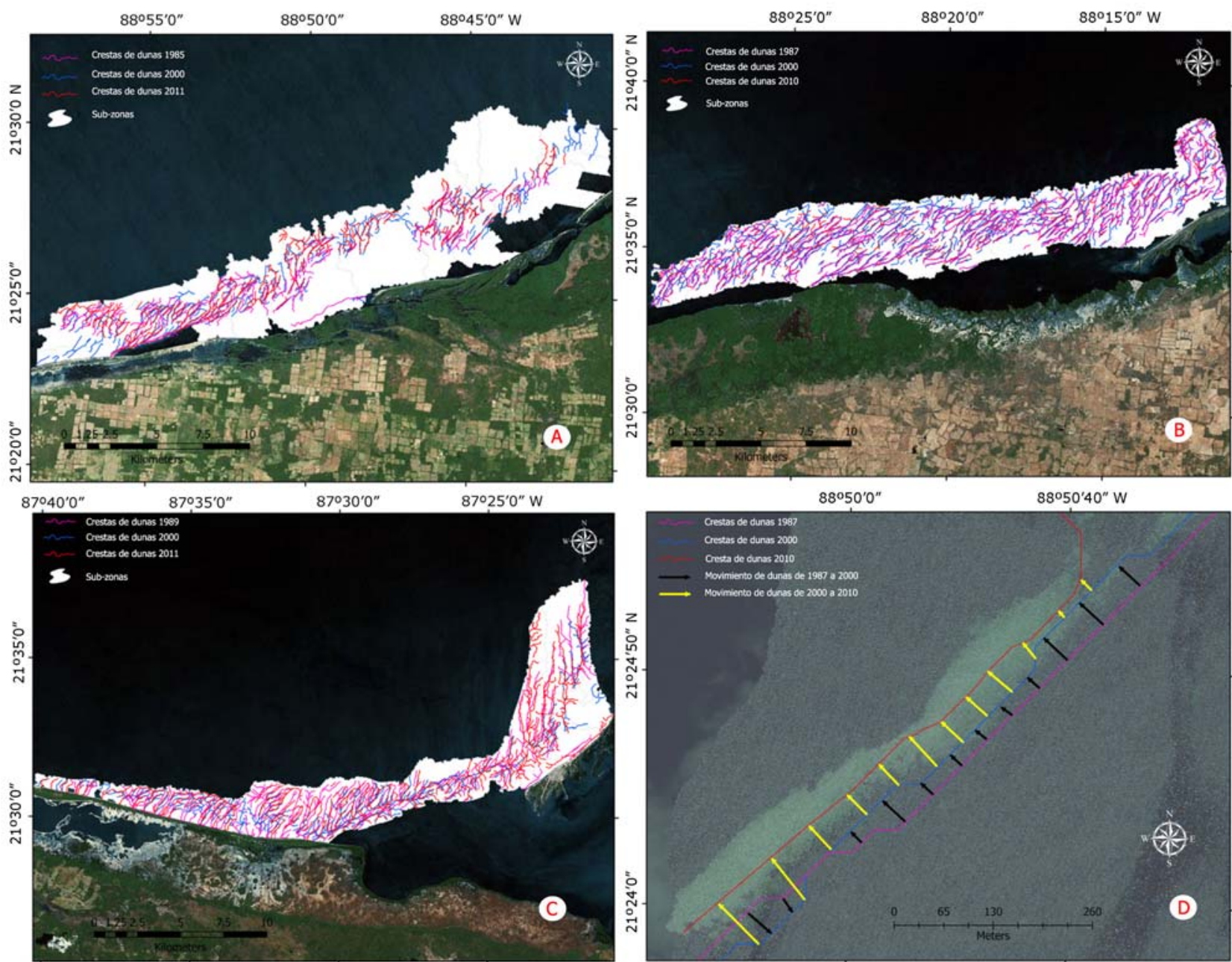

Figura 4. Disposición espacial de los campos de dunas submarinas de Dzilam de Bravo (A), San Felipe (B) y El Cuyo (C), Yucatán, México, en los 3 períodos de tiempo evaluados. Se presenta una ejemplificación del movimiento de una duna submarina dentro del campo de San Felipe (D) / Spatial disposition of the submarine dune fields at Dzilam de Bravo (A), San Felipe (B), and El Cuyo (C), Yucatan, Mexico, on the 3 evaluated periods of time. It is shown an example of the a submarine dune's movement at San Felipe (D)

\section{Dzilam de Bravo}

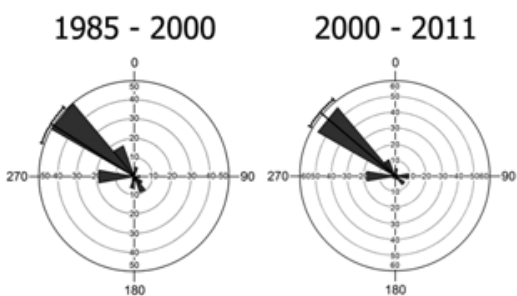

San Felipe

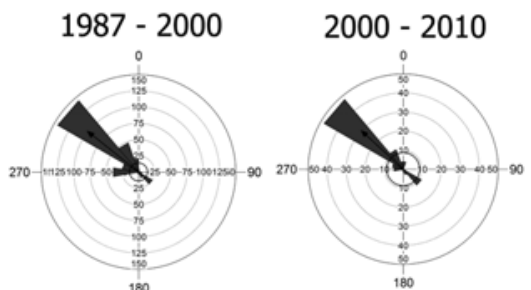

El Cuyo
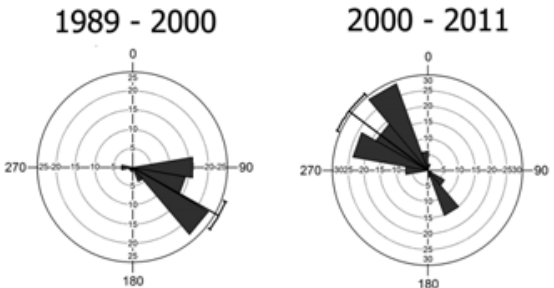

Figura 5. Histogramas circulares de los rumbos de movimiento de las dunas en los campos de dunas de Dzilam de Bravo, San Felipe y El Cuyo, Yucatán, México / Circular histograms showing the bearing of the submarine dunes in the submarine fields at Dzilam de Bravo, San Felipe and El Cuyo, Yucatán, Mexico 

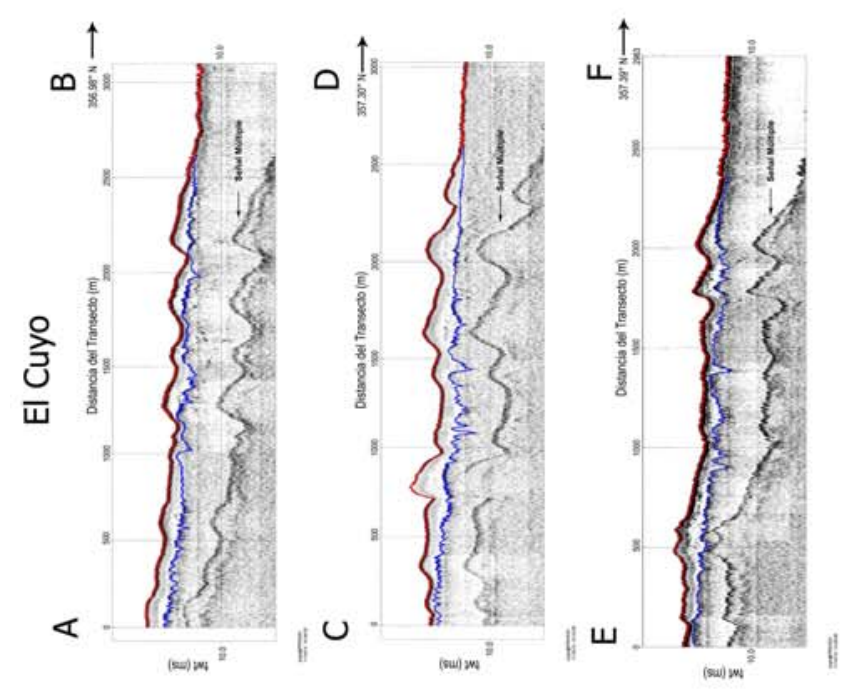

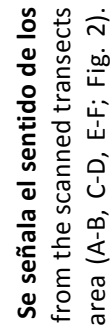

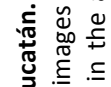

은

플

步

훈음 훙

도웡

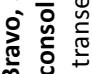

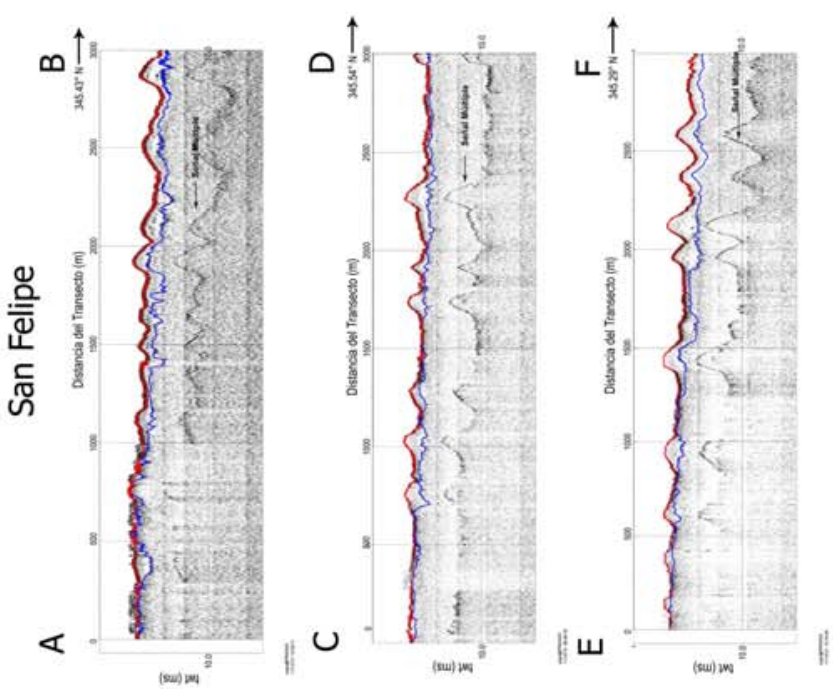

응 융

ह

든

额

륭

은 $\frac{\pi}{2} \frac{5}{4}$

品

डิำ

응

응 율

突它部

으 증 월 웅

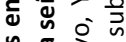

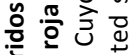

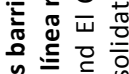

象 ज

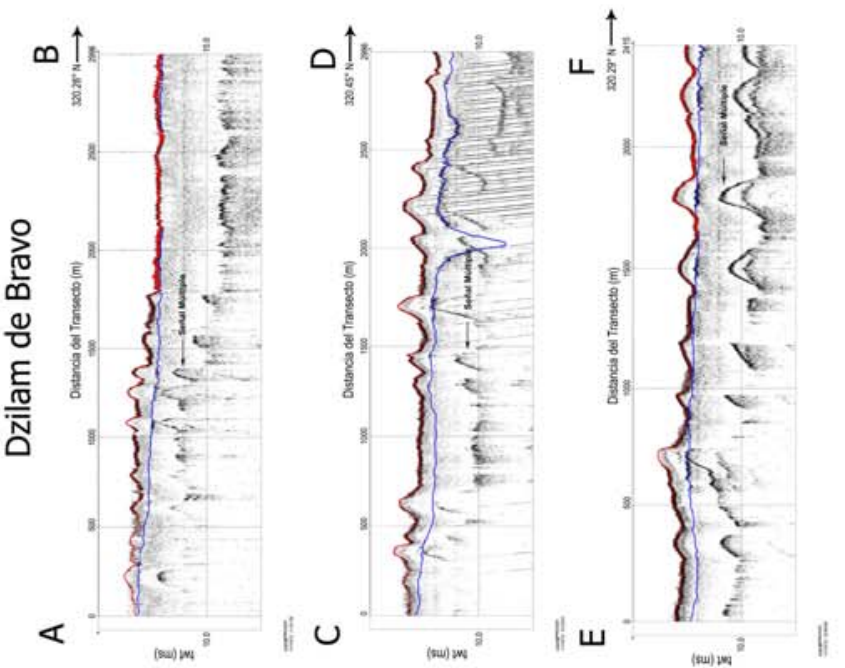

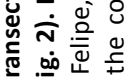

范范芯.

岁客

نั

응 웡

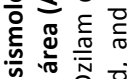

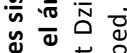

焉

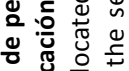

产 专

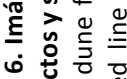

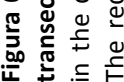




\section{ANÁLISIS SEDIMENTOLóGICo}

Se observó una composición mayor de arena fina y media en las muestras (Fig. 7). En DBR se registró un incremento de la proporción de arena fina en los sitios 2 y 3 ; mientras que en ELC se presentó una tendencia opuesta. En SFE se observó un incremento notable de la proporción de arena fina entre los sitios 2 y 3 , a la vez que el sitio restante no coincidió con esta tendencia, presentando proporciones elevadas de arena gruesa y media.

Con base en los valores promedio del tamaño medio de grano (D50), y el valor de la media de los parámetros estadísticos de los sedimentos, en DBR y SFE se registró sedimento del tipo arena media, y arena fina en ELC (Tabla 4). Es importante mencionar que el valor D50 para la clasificación del sedimento en ELC fue cercano al rango para su clasificación como arena media.

En DBR se registró un sedimento moderadamente clasificado, mientras que en SFE y ELC fueron sedimentos pobremente clasificados. De igual forma, se registró una asimetría negativa de los sedimentos en las 3 localidades; con una marcada distribución leptocúrtica en DBR y SFE, mientras que en ELC se registró una distribución mesocúrtica.

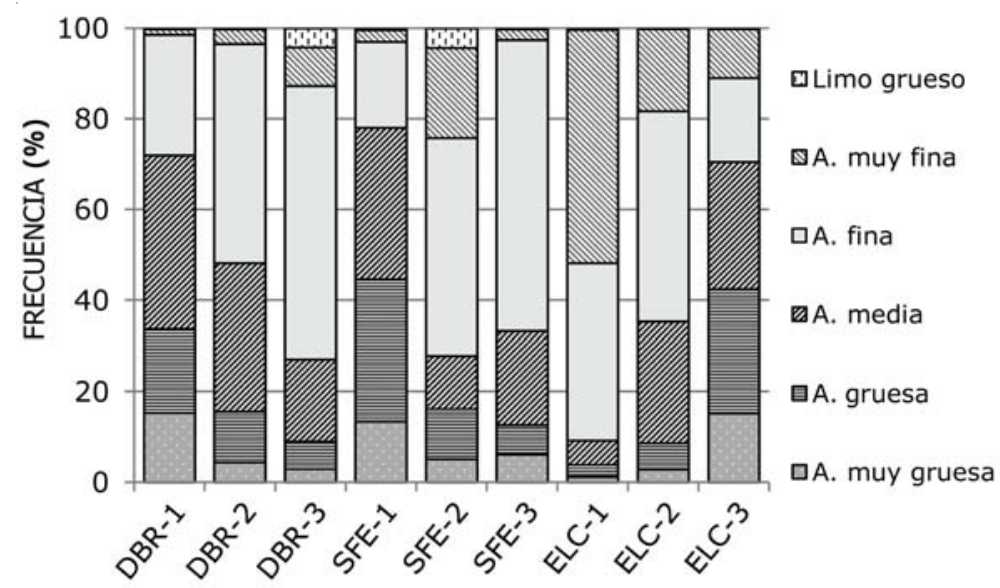

Sitios de muestreo

Figura 7. Distribución sedimentológica de las muestras de sedimento superficial colectadas en Dzilam de Bravo (DBR), San Felipe (SFE) y El Cuyo (ELC), Yucatán / Surface sediment grain size distribution at Dzilam de Bravo (DBR), San Felipe (SFE), and El Cuyo (ELC), Yucatán

Tabla 4. Resumen de los parámetros estadísticos granulométricos promedio de las muestras de sedimento en 3 áreas de estudio / Summary of the granulometric parameter values for the sediment samples from 3 study localities

\begin{tabular}{|c|c|c|c|c|}
\hline Sitio & Prom. (D. E.) & Desviación Estándar & Asimetría & Curtosis \\
\hline Dzilam de Bravo & $1,82(0,48)$ & $0,99(0,16)$ & $-0,22(0,04)$ & $1,17(0,38)$ \\
\hline$(\mathrm{D} 50=269 \mu \mathrm{m})$ & Arena media & Moderadamente clasificado & Asimétrico hacia gruesos & Leptocurtico \\
\hline San Felipe & $1,84(0,58)$ & $1,07(0,16)$ & $-0,23(0,22)$ & $1,193(0,18)$ \\
\hline$(\mathrm{D} 50=279 \mu \mathrm{m})$ & Arena media & Pobremente clasificado & Asimétrico hacia gruesos & Leptocurtico \\
\hline El Cuyo & $2,18(0,81)$ & $1,03(0,29)$ & $-0,11(0,15)$ & $1,02(0,07)$ \\
\hline$(\mathrm{D} 50=245 \mu \mathrm{m})$ & Arena fina & Pobremente clasificado & Asimétrico hacia gruesos & Mesocurtico \\
\hline
\end{tabular}




\section{Discusión}

\section{ESTRUCTURA ESPACIAL DE LOS CAMPOS DE DUNAS}

Se reconoce la formación de campos de dunas submarinas cercanos a la línea de costa, asociados a cambios en la orientación de la misma respecto a la orientación del oleaje dominante (Appendini et al. 2012), campos que suelen tener una permanencia en el largo plazo (Peterson et al. 2010).

En la costa de Yucatán existen segmentos del litoral con marcados cambios de orientación respecto al margen costero general, formando playas protegidas que se sugiere tienen una incidencia distinta del oleaje sobre su litoral respecto al resto de la costa yucateca, con una velocidad de transporte sedimentario reducida (Appendini et al. 2012, Peterson et al. 2010).

El transporte de sedimento en esta región es favorecido por vientos dominantes provenientes del noreste y sureste, que contribuyen a explicar el sentido del movimiento estimado de las dunas (Baillard 1981, Christiansen et al. 2006, Enríquez et al. 2010).

El transporte sedimentario en la zona marina no sigue los mismos patrones que los fluidos en cuencas; sin embargo, el análisis basado en redes de flujos en cuencas, como el aquí utilizado, se sustenta en el reconocimiento de que las dunas submarinas de arena son un mecanismo de transporte de sedimento en ambientes marinos ( $\mathrm{Xu}$ et al. 2008) y se ha reportado que éstas crecen por pasos o saltos, es decir, la unión de 2 o más dunas menores para formar una duna de mayor complejidad y tamaño (Flemming 2000).

En este análisis fue posible identificar dunas cuyo movimiento en el período de más de 20 años fue menor incluso a $1 \mathrm{~m}$, valores que no se ven reflejados de manera puntual en los datos reportados, pero sí en la variabilidad de sus movimientos registrados. Este comportamiento es consistente con información sobre dunas grandes y embebidas en bancos de arena persistente en el tiempo, los cuales mencionan que su forma comúnmente no varía y permanece por décadas en la misma posición (Van Lancker \& Jacobs 2000).

Una posible explicación de estas dunas perdurables es el proceso de cimentación por cambios en el nivel del mar, así como por acción misma de las mareas en la zona (Peterson et al. 2010). Al respecto existe información anecdótica local de la emersión temporal de algunas de las dunas estudiadas, así como de la información paleológica de inundación de grandes extensiones de la península por ascensos de más de $100 \mathrm{~m}$ sobre el nivel medio del mar en eras pasadas para la península de Yucatán (Lugo-Hubp et al. 1992).

Otro factor de gran relevancia a considerar es que el área de estudio se encuentra ubicada en una zona que coincide con la trayectoria de huracanes y tormentas de gran magnitud en la región. Dada la escala espacial empleada en este estudio (más de 10 años), no fue posible evaluar las alteraciones por estos fenómenos meteorológicos, puesto que la aproximación propuesta y objetivo principal del estudio, permitió solamente evaluar el resultado acumulado de los cambios en las dunas por estos fenómenos en el período decadal.

Por otro lado, derivado de la identificación de jerarquías de complejidad en los campos de dunas entre años, fue posible distinguir períodos en que las dunas más simples disminuyen y el número de dunas de jerarquía media y alta se incrementa. Esto se explicaría por la unión de 2 o más dunas para generar una más conspicua (Flemming 2000).

Por el contrario, una disminución de las jerarquías más altas sugiere la presencia de eventos que segmentan o merman dichas dunas, como pueden ser los huracanes o vientos del norte de gran magnitud en la región. Estas variaciones en las proporciones de jerarquías de dunas con base en el índice Horton son un indicio del sentido de la dinámica del campo de dunas en espacio y tiempo.

\section{MovimiEnTo DE LAS DUNAS}

De manera general, los campos de dunas en los 3 sitios se desplazan con movimientos en diferentes sentidos y tiempos. El movimiento neto estimado de las dunas es el resultante de cualquier movimiento de avance y retroceso entre años evaluados, reconociendo un potencial enmascaramiento de movimientos en los años no evaluados y por tanto no detectados. El reconocimiento y consideración de esta limitante por la resolución temporal en el estudio no demerita la propuesta de aproximación metodológica. La disponibilidad de series de tiempo de imágenes satelitales (en este caso Landsat) con la calidad de adquisición y nubosidad aptas para este tipo de análisis es pobre, lo que dificulta conformar una serie de tiempo con intervalos de un año, por ejemplo.

El rango de movimiento anual estimado de las dunas en SFE y DBR, en zonas con presencia de pastos marinos 
entre dunas (Herrera-Silveira et al. 2010), fue entre 2,94 y $4,01 \mathrm{~m}$ año $^{-1}$, valores inferiores a los reportados por Daniell et al. (2008) para dunas al norte de Australia con pastos marinos intercalados entre ellas, con movimientos de hasta $108 \mathrm{~m}_{\text {año }}{ }^{-1}$. De igual forma, reportan una frecuencia de enterrado de las praderas de pastos de 1 vez hasta cada 100 años (Daniell et al. 2008). Las condiciones que determinan la presencia de pastos marinos dentro de los campos de dunas son de relevancia para el estudio de la dinámica detallada de las dunas; sin embargo, dados los alcances y objetivos del presente estudio, no se recopilaron mayores datos sobre características de los pastos marinos en estas localidades, quedando este punto como una línea de investigación por atender en el marco del estudio de la dinámica de las dunas en la región.

Por el contrario, en la zona de ELC no se observaron praderas de pastos de alta densidad como en los otros 2 sitios, principalmente en la zona oriente de dicha área donde las condiciones observadas sugieren la presencia de un banco de arena cuya hidrología se consideraría hostil para el asentamiento de pastos marinos como lo sugieren Daniell et al. (2008).

En condiciones físicas distintas a las del presente estudio, Aliotta \& Perillo (1987) reportaron movimientos de dunas de $360 \mathrm{~m}$ año ${ }^{-1}$, mientras que Dalrymple \& Rhodes (1995), así como Gómez et al. (2010) reportaron movimientos entre $25 \mathrm{~m}$ año $0^{-1}$ y $135 \mathrm{~m}_{\text {año }}{ }^{-1}$ en estuarios. Estos datos son presentados como valores referenciales, más no comparativos debido a las condiciones oceanográficas distintas entre los ambientes estudiados.

En lo que se refiere al rumbo del movimiento de las dunas, de manera general se sabe que éstas migran en la dirección del máximo transporte de arena en la zona (Xu et al. 2008), y en la costa de Yucatán es de este a oeste, con un transporte de sedimento resultante hacia el noroeste (Mariño-Tapia et al. 2012 datos no publicados ${ }^{5}$, Appendini et al. 2012).

La diferencia en el rumbo de movimiento de las dunas en ELC, de este-sureste, respecto al dominante hacia el noroeste, puede ser resultado de la variabilidad en el clima de oleaje y corrientes en esta zona que se encuentra aledaña a la boca de la laguna costera Conil (Isla Holbox) y que, junto con su orientación de la costa, presentan condiciones particulares de deposición de sedimento.

\section{AnÁLisis SEdimentológico}

Dada la naturaleza de verificación de la información de las imágenes satelitales, el número de muestras colectadas de sedimento es pequeño, aportando información puntual en estas localidades. Cuevas et al. (2013) proveen mayor información sedimentológica.

Se infiere que la presencia de arena media en DBR y SFE es indicadora de un ambiente con energía hidrodinámica (corrientes, vientos, oleaje y mareas) moderada. Esta inferencia coincide con las descripciones de potencial de transporte sedimentario costero para estas 2 localidades por Appendini et al. (2012).

Por su parte, en ELC se reconocen diferencias entre las características sedimentológicas aquí reportadas y lo señalado por Cuevas et al. (2013), lo cual es explicable por la diferencia en las temporadas climáticas de las colectas entre estudios, así como por las características de oleaje y orientación de la costa descritas para esa localidad en particular por Appendini et al. (2012), reconociéndole como una zona de acumulación de sedimento con características de circulación excepcionales al encontrarse influenciados por la entrada a la Laguna Yalahau al oriente de ELC.

De acuerdo a los resultados obtenidos, se rechazó la hipótesis postulada al inicio, tanto en SFE como en ELC se reportan tasas de movimiento neto de las dunas distintas entre los 2 períodos evaluados, siendo DBR la única localidad en la que los movimientos de las dunas fueron similares entre períodos. Los movimientos de las dunas se dan en un rumbo definido y concentrado alrededor de una media dada para cada localidad.

Ante los problemas erosivos en la zona, estos bancos de arena tendrían el potencial de ser una fuente de sedimento para las playas degradadas; sin embargo, es necesario caracterizar y evaluar de manera crítica la función ecológica de estos 'bajos' tanto para las comunidades bentónicas y demersales que lo habitan, como para los asentamientos humanos en la región, antes de cualquier intervención.

El uso de imágenes satelitales para el seguimiento de las dunas submarinas detectables en ellas mostró ser útil e innovador. En la literatura disponible no se encontraron otros casos de estudio en los que se recurra a la percepción remota para evaluar la estructura espacial y

${ }^{5} 31$ st Meeting of the Conference of Latin Americanist Geographers. Mérida, Yucatán, México. Enero 11-13, 2012 
cambios en el tiempo de campos de dunas sumergidas. Solamente se advirtió de un estudio que utilizó imágenes satelitales para evaluar sedimentos suspendidos en India (Subramanian et al. 1988), y otro para dunas eólicas (Hugenholtz et al. 2012).

La presente aproximación metodológica aporta una visión espacial integral de la disposición de las dunas submarinas con un método estandarizado para reconocimiento de éstas, y contribuyó con una primera evaluación de tasas de movimiento de dunas en períodos de más de 2 décadas y de forma retrospectiva, lo cual de otra forma sería imposible de realizar.

Esta aproximación tiene limitaciones, entre las que resaltan la resolución espacial $(28 \mathrm{~m})$ que influye en el poder de detección de movimientos de las dunas, la normalización de las condiciones atmosférica y de transparencia de la columna de agua entre imágenes de años distintos, así como la escasa disponibilidad de imágenes con las condiciones de luz y transparencia óptimas que permitieran una evaluación temporal más detallada.

\section{Agradecimientos}

Los autores expresan su agradecimiento al Fondo Mixto CONACYT - Gobierno del Estado de Yucatán por el financiamiento del proyecto \#108960 en el que se enmarca este estudio. A la empresa IHS Inc. por su aportación con apoyo en el software para análisis académicos que se incluyen en este estudio. A los evaluadores y Comité Editorial por sus comentarios importantes y enriquecedores para la integración final de este manuscrito.

\section{LITERATURA CITADA}

Aliotta S \& GME Perillo. 1987. A sand wave field in the entrance to Bahia Blanca estuary, Argentina. Marine Geology 76: $1-14$.

Álvarez-Góngora C \& JA Herrera-Silveira. 2006. Variations of phytoplankton community structure related to water quality trends in a tropical karstic coastal zone. Marine Pollution Bulletin 52: 48-60.

Appendini CM, P Salles, ET Mendoza, J López \& A TorresFreyermuth. 2012. Longshore sediment transport on the northern coast of the Yucatan Peninsula. Journal of Coastal Research 6: 1404-1417.

Baillard JA. 1981. An energetic total load sediment transport model for a plane sloping beach. Journal of Geophysical Research 86: 10938-10954.
Bartholdy J, BW Flemming, A Bartholomä \& VB Ernstsen. 2004. On the dimensions of depth-independent, simple subaqueous dunes. In: Hulscher S, T Garlan \& D Idier (eds). Proceedings of Marine Sandwave and River Dune Dynamics International Workshop, April 1-2 2004, University of Twente, Enschede, The Netherlands, pp. 9-16.

Bindschadler RA \& TA Scambos. 1991. Satellite-ImageDerived velocity field of an Antarctic ice stream. Science 252: 242-252.

Cabadas-Báez H, E Solleiro-Rebolledo, S Sedov, T Pi-Puig \& J Gama-Castro. 2010. Pedosediments of karstic sinkholes in the eolianites of NE Yucatán: A record of Late Quaternary soil development, geomorphic processes and landscape stability. Geomorphology 122: 323-337.

Capurro L. 2002. Un gran ecosistema costero: La península de Yucatán. Avance y Perspectiva 22: 69-75.

Capurro L, J Euán \& J Herrera. 2002. Manejo sustentable del ecosistema costero de Yucatán. Avance y Perspectiva 21: 195-204.

Christiansen C, G Volund, LC Lund-Hansen \& J Bartholdy. 2006. Wind influence on tidal flat sediment dynamics: Field investigations in the Ho Bugt, Danish Wadden Sea. Marine Geology 235: 75-86.

Cuevas-Jiménez A \& J Euán-Ávila. 2009. Morphodynamics of carbonate beaches in the Yucatan peninsula. Ciencias Marinas 35(3): 307-320.

Cuevas E, MA Liceaga-Correa, LA Rincón-Sandoval, G Mexicano-Cíntora, L Arellano-Méndez, J Euán-Ávila, H Hernández-Núñez \& S Mulsow. 2013. Morphological and sedimentological assessment of submarine dune fields on the coast of Yucatan, Mexico. Ciencias Marinas 39(1): 83-99.

Dalrymple RW \& RN Rhodes. 1995. Estuarine dunes and bars. In: Perillo GME (ed). Geomorphology and sedimentology of estuaries. Developments in Sedimentology 53: 359-422. Elsevier, Amsterdam.

Daniell JJ, PT Harris, MG Hughes, M Hemer \& A Heap. 2008. The potential impact of bedform migration on seagrass communities in Torres Strait, northern Australia. Continental Shelf Research 28: 2188-2202.

Enriquez C, IJ Mariño-Tapia \& JA Herrera-Silveira. 2010. Dispersion in the Yucatan coastal zone: Implications for red tide events. Continental Shelf Research 30: 127-137.

Ernstsen VB, R Noormets, D Hebbeln, A Bartholomä \& BW Flemming. 2006. Precision of high-resolution multibeam echo sounding coupled with high-accuracy positioning in a shallow water coastal environment. GeoMarine Letters 26: 141-149.

Flemming BW. 2000. The role of grain size, water depth and flow velocity as scaling factors controlling the size of subaqueous dunes. In: Trentesaux A, T Garlan \& S Le Bot (eds). Proceedings of Marine Sandwave Dynamics International Workshop, March 23-24 2000, University of Lille, France, pp. 55-60. 
Folk RL. 1980. Petrology of sedimentary rocks, 182 pp. Hemphill, Austin.

Garlan T, Y Le Faou, P Guyomard \& I Gabelotaud. 2008. French marine sand dune project. In: Parsons D, T Garlan \& J Best (eds). Proceedings of Marine and River Dune Dynamics 3: 133-139, International Workshop, April 1-3 2008, University of Leeds, United Kingdom.

Gómez EA, DG Cuadrado \& JO Pierini. 2010. Sand transport on an estuarine submarine dune field. Geomorphology 121: 257-265.

Hequette A \& D Aernous. 2010. The influence of nearshore sand bank dynamics on shoreline evolution in a macrotidal coastal environment, Calais, northern France. Continental Shelf Research 30: 1349-1361.

Herrera-Silveira J, S Morales-Ojeda \& J RamírezRamírez. 2010. Plantas marinas. En: Durán R \& M Méndez (eds). Biodiversidad y desarrollo humano en Yucatán, pp. 197-200. CICY, PPD-FMAM. CONABIO, SEDUMA, México.

Houthuys R, A Trentesaux \& P De-Wolf. 1994. Storm influences on a tidal sandbank's surface (Middelkerke Bank, southern North Sea). Marine Geology 121: 23-41.

Hugenholtz CH, N Levin, TE Barchyn \& MC Baddock. 2012. Remote sensing and spatial analysis of aeolian sand dunes: A review and outlook. Earth-Science Reviews 111: 319-334.

Larcombe P \& RM Carter. 2004. Cyclone pumping, sediment partitioning and the development of the Great Barrier Reef shelf system: a review. Quaternary Science Review 23: 107135.

Le Bot S \& A Trentesaux. 2004. Architecture of very large submarine dunes influenced by tide- and wind-generated processes (Dover Strait, northern France). In: Hulscher S, T Garlan \& D Idier (eds). Proceedings of Marine Sandwave and River Dune Dynamics International Workshop, April 1-2 2004, University of Twente, Enschede, The Netherlands, pp. 184-191.

Lugo-Hupb J, JF Aceves-Quesada \& R Espinasa-Pereña. 1992. Rasgos geomorfológicos mayores de la península de Yucatán. Revista Mexicana de Ciencias Geológicas 10(2): 143-152.

Mumby P \& A Edwards. 2000. Water column correction techniques. In: Green EP, PJ Mumby, AJ Edwards \& CD Clark (eds). Remote sensing handbook for tropical coastal management. Coastal Management Sourcebook 3: 121-128. UNESCO, Paris.
Perry E, A Paytan, B Pedersen \& G Velazquez-Oliman. 2009. Groundwater geochemistry of the Yucatan Peninsula, Mexico: Constraints on stratigraphy and hydrogeology. Journal of Hydrology 367: 27-40.

Peterson CD, E Stock, R Hart, D Percy, SW Hostetler \& JR Knott. 2010. Holocene coastal dune fields used as indicators of net littoral transport: West Coast, USA. Geomorphology 116: 115-134.

Scambos TA, MJ Dutkiewicz, JC Wilson \& RA Bindschadler. 1992. Application of image cross-correlation to the measurement of glacier velocity using satellite image data. Remote Sensing Environment 42: 177-186.

Schmitt T, NC Mitchell \& TS Ramsay. 2007. Use of swath bathymetry in the investigation of sand dune geometry and migration around a near shore 'banner' tidal sandbank. Coastal and Shelf Sediment Transport, Geological Society of London 274: 53-64.

Smith RB. 2010. Modeling watershed geomorphology. Tutorial with TNTmips, 28 pp. Microimages, Nebraska < http:// www.hesc.it/tnt/tutorial/watershd-ENG.pdf >

Solleiro-Rebolledo E, HV Cabadas-Báez, PT Pi, A González, SL Fedick, JA Chmilar \& D Leonard. 2011. Genesis of hydromorphic Calcisols in wetlands of the northeast Yucatan Peninsula, Mexico. Geomorphology 135: 322-331.

Subramanian SK, K Keshavasamy, K Hanumantha-Rao \& SK Bhan. 1988. Coastal geomorphology and sediment distribution mapping using Landsat-TM digital data - A study in coastal area of parts of Orissa, India. Journal of the Indian Society of Remote Sensing 3: 1-6.

Tucker ME \& VP Wright. 1990. Carbonate sedimentology, 481 pp. Blackwell Science, Oxford.

Van Dijk TAGP \& MG Kleinhans. 2005. Processes controlling the dynamics of compound sand waves in the North Sea, Netherlands. Journal of Geophysical Research 110, <doi:10.1029/2004JF000173>

Van Lancker VRM \& P Jacobs. 2000. The dynamical behaviour of shallow-marine dunes. Marine Sandwave Dynamics 23 \& 24: 213-220.

Xu JP, FL Wong, R Kvitek, DP Smith \& CK Paull. 2008. Sandwave migration in Monterey submarine canyon, central California. Marine Geology 248: 193-212.

Zar JH. 1994. Biostatistical analysis, 663 pp. Prentice-Hall, Upper Saddle River.

Recibido el 9 de julio de 2012 y aceptado el 28 de febrero de 2013

Editor: Claudia Bustos 